\title{
(2)
}

\section{COMBUSTION OF BIOFUELS-DIESEL BLENDS IN AN ISOTHERMAL OVEN}

\section{TOLEDO M. ${ }^{*}$ JIMÉNEZ J. CÁRDENAS L. GERS R. ESPINOZA J.}

Received: 07/06/2014

Accepted: 20/12/2014

Available online: 25/02/2015

\author{
Department of Mechanical Engineering \\ Universidad Técnica Federico Santa María
}

Av. España 1680, Valparaíso, Chile

\section{ABSTRACT}

In this work, combustion process of diesel and biofuel blends is studied experimentally in an isothermal oven. Blends with respectively $20 \%, 40 \%$ and $60 \%$ of Ethanol (E20, E40, E60), 20\%, 40\% and 60\% of Methanol (M20, M40, M60), and 20\%, 40\%, 60\%, 80\% and 100\% of Biodiesel (B20, B40, B60, B80, B100), are comparatively analyzed focusing on wall temperature of the isothermal oven and emissions products from combustion. It is found that wall temperature drops with biodiesel content in blends and is higher compared with pure diesel, whatever the content of biodiesel. For diesel-ethanol and diesel-methanol blends the wall temperature is less than pure diesel. Unburned $\mathrm{HCs}$ and $\mathrm{NO}_{\mathrm{x}}$ emissions are very low for all blends and CO emissions increase with higher ethanol and methanol blends. For industrial applications that need high temperature (as drying, cooking, sterilization, others) the combustion of diesel-biodiesel blends are recommended.

Keywords: Biofuels, Diesel, Combustion, Isothermal oven, Emissions

\section{Introduction}

For the last years, there is a strong trend to find new environment-friendly and renewable fuels to bring a solution to the problematic energy shortage and polluting emissions, mainly due to the increase of energy consumption (Carraretto et al., 2004; Barroso et al., 2010). Biodiesel has recently drawn the attention because is a renewable biological resource which results from the reaction of lipids (vegetable oil and animal fats) with an alcohol, producing fatty acid esters. It seems to present an alternative to diesel fuel according to its attractive characteristics: not toxic, biodegradable, sulfur-free, carbon neutral, oxygenated, and particulate emitter than a pure diesel fuel, and renewable. Moreover, biodiesel can be handled and transported in a safer manner than diesel due to its lower volatility and its relatively high flash point (Freedman et al., 1984; Freedman et al., 1986; Schwab et al., 1987; Shay, 1993).

Tashtoush et al. (2003), conducted tests burning diesel and ethyl ester from a waste vegetable oil in water-cooled furnace, at different air-fuel ratio and two different fuel flows. They showed that biodiesel has a greater combustion efficiency and higher exhaust gas temperature for lower fuel flow than diesel. But at high energy intakes, combustion performance of biodiesel decreases, basically due to its high 
viscosity, high density, and low volatility. Nevertheless, fewer emissions are obtained with biodiesel in both systems.

The addition of alcohols in diesel or biodiesel was study to take the advantages of less particle emissions from the biodiesel combustion and less $\mathrm{NO}_{x}$ from the diesel combustion. Papers studied the mixture of alcohols, as ethanol and methanol, with diesel fuel (Fang et al., 2013). They are used as a fuel additive. Their presence increases the oxygen content of the fuel which helps to reach a more completed combustion. For example, Barroso et al. (2010), used an industrial burner to compare the performance of bio-ethanol and diesel in a vertical boiler. Tests were carried out in two ways: first with similar fuel flows; second with similar thermal potential, successfully adjusting nozzle and injection pressures. Authors conclude that substituting bio-ethanol is technically feasible, provided that modifications are made to the boiler and burner. These modifications also contribute to reduced emissions of contaminants. Combustion tests show important differences between bio-ethanol and diesel. Indeed, $\mathrm{NO}$ and sulphur dioxide $\left(\mathrm{SO}_{2}\right)$ emissions are significantly lower with ethanol but fuel could produce higher amounts of $\mathrm{CO}$ than gasoil if the burner is not properly adapted.

All research reported mainly evaluate performance and emissions of blends but not shows its results on applications to industrial process. In real applications as boiling (Ghorbani et al., 2011; GonzálezGonzález et al., 2014), pulverization burner (San José et al., 2011), emulsion burner (San José et al., 2015), vaporizing oil (Barnes et al., 2010) and biscuit baking tunnel oven (Mirade et al., 2004), knowing the flame temperature is required.

This work aims to determine the combustion process of diesel-biodiesel blends or diesel-alcohol blends and its results on wall temperature of isothermal oven in an industrial burner. Blends are made of diesel and $20 \%-40 \%-60 \%$ of ethanol (E20, E40, E60), diesel and $20 \%-40 \%-60 \%$ of methanol (M20, M40, M60), diesel and $20 \%-40 \%-60 \%-80 \%-100 \%$ of biodiesel (B20, B40, B60, B80, B100). The analyzed parameters are gas emissions, thermo-physical properties, and wall temperature of isothermal oven. Diesel and biofuel blends are burner under similar conditions in a burner coupled to anisothermal oven.

\section{Design and experimental procedure}

\subsection{Thermo-physical properties}

Before testing diesel and biofuel blends, it is necessary to determine their thermo-physical properties. That is why representative samples of each one are analyzed to measure the viscosity, density, flash point, and minimum calorific value (Table 1).

Table 1: Thermo-physical properties of biofuels and diesel

\begin{tabular}{ccccc}
\hline Fuel & $\begin{array}{c}\text { Flash Point } \\
{\left[{ }^{\circ} \mathbf{C}\right]}\end{array}$ & $\begin{array}{c}\text { Kinematic Viscosity } \\
{\left[\mathbf{m}^{2} \mathbf{~ s}^{-1}\right]}\end{array}$ & $\begin{array}{c}\text { Density } \\
{\left[\mathbf{g ~ c m}^{-3}\right]}\end{array}$ & $\begin{array}{c}\text { Calorific Value } \\
{\left[\mathbf{k J ~ k g}^{-1}\right]}\end{array}$ \\
\hline Diesel & 53.3 & $2.42 \mathrm{e}^{-6}$ & 0.842 & 43,9 \\
\hline Biodiesel & 110.3 & $5.24 \mathrm{e}^{-6}$ & 0.864 & 39,2 \\
\hline Ethanol & $13.0^{*}$ & $1.68 \mathrm{e}^{-6}$ & 0.807 & 26,0 \\
\hline Methanol & $12.2^{* *}$ & $0.69 \mathrm{e}^{-6}$ & 0.796 & 22,0 \\
\hline
\end{tabular}

*Barroso et al., (2010); **Methanex Corporation, (2006).

Density measurements respect the ASTM D1481 method, using a Gamma density-meter which freely floats in a constant temperature bath at $15^{\circ} \mathrm{C}$.

Viscosity is measured by a viscometer Saybolt (E. Machlett \& Son), according to ASTM D88 method: at $40{ }^{\circ} \mathrm{C}$, the time it takes to collect $60 \mathrm{ml}$ provides its value. This method generates SUS units that are converted into cinematic viscosity in IS units. 
Flash point is measured by the close-cup Pensky Martens's method, which consists of a cup with a fixed amount of fuel, an immersed thermometer in the liquid and an agitation. The cup is closed and warmed. Ignition is provided on the top of the cup. When the flame noticeably fills the cup, the flash temperature is reached. This method is based on ASTM D92 and D93 method. This method is only valid for diesel and biodiesel, as ethanol and methanol have flash points that are too low for this test.

Calorific value and other measurements of combustible capacity are done according to ASTM D4809, D271 and D2055. To sum up, the test material is contained in a cup inside a calorimetric pump. A fuse wire, connected to an electrical circuit, is hanged and immersed in the sample. The pump is closed, rinsed with incoming oxygen and pressurized to $30 \mathrm{~atm}$. The test material ignites inside the pump and the released heat is measured by temperature differential of a known water body outside. When combustion is finished, the pump is placed in an oven. Then the gaseous and vapor mixture inside is released through traps of $\mathrm{CaCl}_{2}$ (calcium chloride, in water) by weight differential. Heat capacity and other values are derived by calculations.

Biodiesel (sunflower oil) is denser, more viscous, and has a higher flammable point than conventional petroleum diesel. However, it possesses a lower calorific value. Alcohols such as ethanol and methanol are less dense and viscous than conventional diesel. Besides they have lower flammable points and less calorific value. Diesel and biodiesel are more miscible than alcohols.

The differences properties between alcohols and diesel impose to modify the burner and its functioning in order to promote ethanol and methanol as efficient burning fuels. Barroso et al. (2010), mention changes in the instrumentation and the adaptation of some equipment parts to insure a good combustion. For example, they changed the flame detection because of the differences between flames of both alcohols and diesel. It is also necessary to modify airflow and pressure of injection in order to obtain either similar flows or similar power upon entrances.

\subsection{Procedure and combustion tests}

Studies of diesel and biofuel blends are carried out in an industrial diesel burner LO-60 (CIB-UNIGAS), which has a maximum power of $60 \mathrm{~kW}$ and a maximum flow rate of $5 \mathrm{~kg} \mathrm{~h}^{-1}$.

Diesel and biofuel blends are stored in a $45 \mathrm{~L}$ tank and are pumping with a Suntec AS47-A pump, having a maximum discharge pressure of $1.4 \mathrm{MPa}$. Fuel is spraying by a Danfoss pressure-swirl nozzle $60 \mathrm{~S}$ nominal, with a maximum flow of $3.785 \mathrm{~L} \mathrm{~h}^{-1}$. The isothermal oven consists of a combustion chamber, a refrigerated chamber and a heat exchanger. The diameter and the length of the combustion chamber are fixed $(540 \mathrm{~mm}$ and $1350 \mathrm{~mm}$ respectively). The oven, insulated with a refractory material (Plastigreen, Lota Green), is surrounded by a cooling water circuit which maintains a stable temperature profile. The isothermal oven requires two independent sources: one for the heat exchanger (one pass, sent to waste) and a second for the refrigerated chamber. The last one provides a constant water level thanks to a compensation tank which allows water to expand when temperature increases. Water enclosed in the refrigerated chamber circulates through the heat exchanger by using an electric rotary pump. Figure 1 shows the schematic design of the equipment. Further information is detailed in Saez et al. (2012).

Twelve thermocouples, type $\mathrm{R}$ ( $0.75 \mathrm{~mm}$ in diameter, platinum-rhodium coating with $13 \%$ of rhodium) and type $\mathrm{K}$ (1.5 mm in diameter, chromel-alumel coating) made by OMEGA are connected to different parts of the equipment: T1 to T5 are attached to the wall oven, while T9 to T12 monitor temperature of water flow in different locations. An OMB DAQ 54 acquisition module collects the voltages measured by the thermocouples and converted by the Personal DaqView Software. 
Effluent gases of the combustion are analyzed by two flue-gas meters, Testo 350-S and Bosh BEA 250 EU. Gases are monitored at the end of the vent pipe by both instruments. The gases CO, unburned HCs, and NOx are tracked.

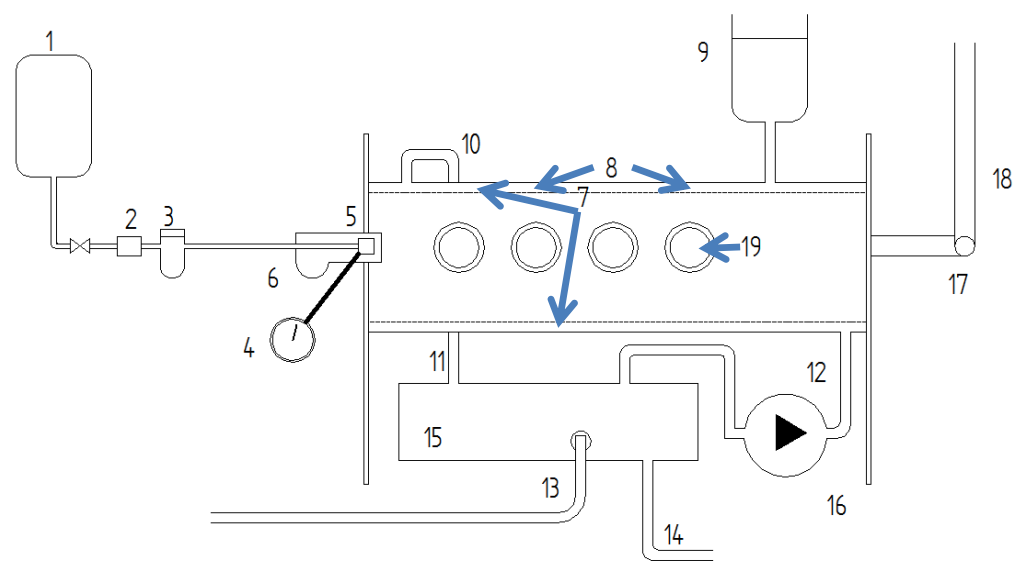

Figure 1: Schematic arrangement of the equipment: (1) Fuel tank; (2) Fuel flow control; (3) Fuel filter; (4) Pressure Gauge; (5) Fuel pump; (6) Burner; (7) Refrigerated chamber; (8) Temperature control and sensors T1 to T5; (9) Expansion tank; (10) Control for circulating water; (11) Oven temperature outlet; (12) Oven temperature inlet; (13) Exchanger temperature inlet; (14) Exchanger temperature outlet; (15) Exchanger; (16) Circulation pump; (17) Vent pipe; (18) Emission control and exit temperature; (19) Flame observation window.

The methodology, which permits to compare the combustion process of blends, is based on triplicate measurements for each blend. Throughout the experiments, the injection pressure is fixed to 8 bars, the mechanical air opening to a constant value and a pressure of 0.6 bar is imposed in the circulation pump. Each experiment is initiated with a volumetric fuel mixture of pre-determined percentages. Fuels are mixed in bottles of $500 \mathrm{~mL}$ and $250 \mathrm{~mL}$, and then transferred to a $2 \mathrm{~L}$ graduated cylinder. A big care is brought to the preservation of the homogeneity of the mixture in the time. After the start-up of the equipment, a start up period of $30 \mathrm{~min}$ is established to attain stable conditions. The flow rate of the refrigerated water is determined according to the water consumption of the system. Temperatures of the process and of the sampled effluent gases are recorded by the computer.

\section{Analysis of results}

\subsection{Wall temperature of the oven}

The study of the influence of the burned blend on the temperatures inside the isothermal oven is focused as special matter of interest. Moreover the temperature evolution for a same blend indicates if the combustion is stable or not. All the results presented in this paper are taken when the temperature is stable. Figure 2 shows positions of the thermocouples from T1 to T5 which give the wall temperatures inside the oven. The average temperatures for each measure point are shown in Figure 3. In this figure, it can be seen first that temperatures given by $\mathrm{T} 2$ and $\mathrm{T} 4$ are close as measure points are close for all blends. Temperatures given by $\mathrm{T} 1$ and $\mathrm{T} 3$ are close too for the same reason. Secondly, it appears that temperatures in each measure point present a similar trend. Compared to pure diesel, temperatures for methanol and ethanol blends are lower and decrease as the percentage of alcohol increases. On the contrary, temperatures for biodiesel-diesel blends are higher than these for pure diesel and increase as 
the percentage of biodiesel increases. The higher combustion temperature of biodiesel blends can be explained by oxygen content in the biodiesel, which is favorable to the combustion process.

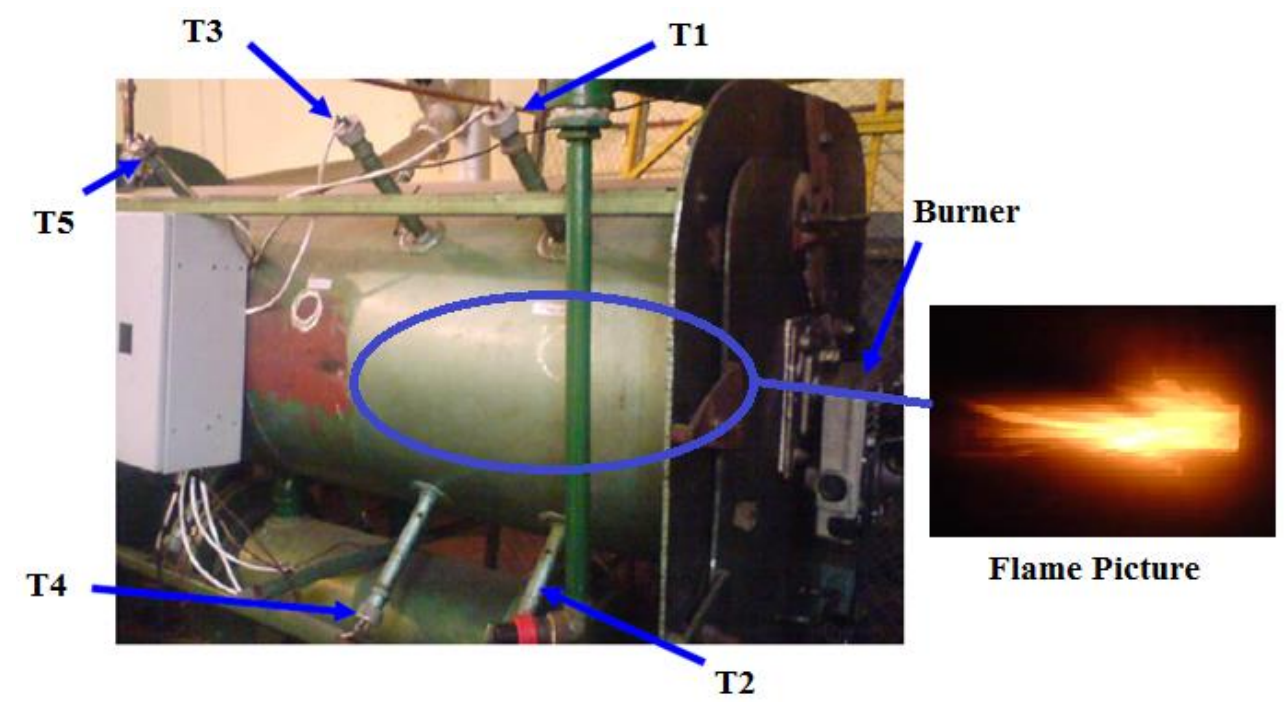

Figure 2: Thermocouple position in the isothermal oven

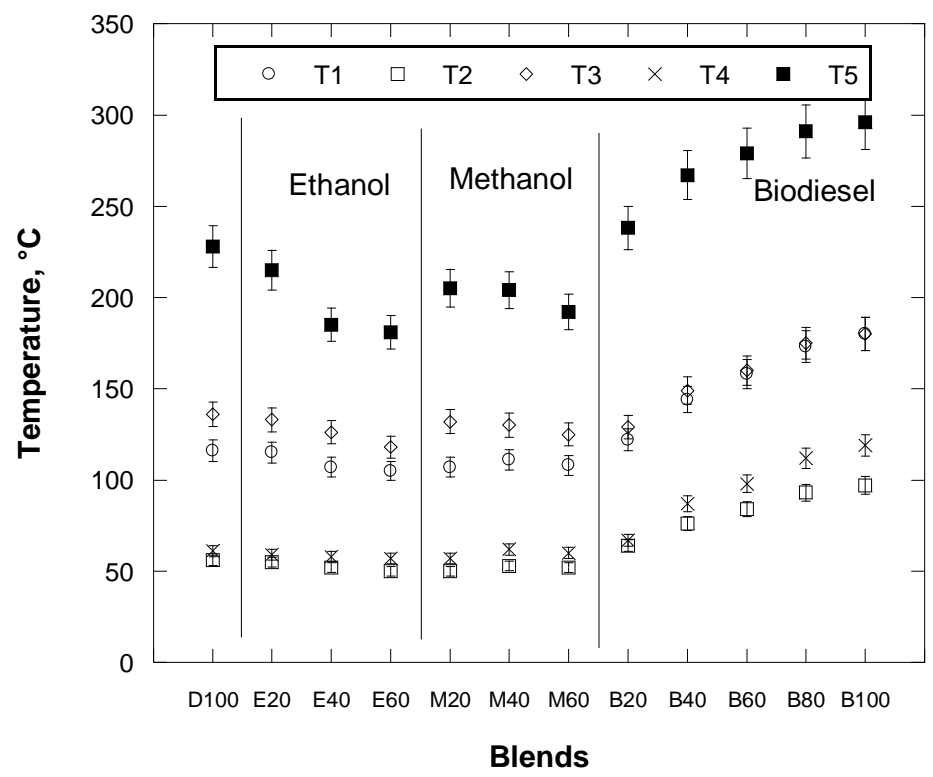

oven for each blend.

Figure 3: Wall temperature in isothermal

\subsection{Concentrations of the effluent gases}

In the case of pure diesel, burning conditions are established and blends are combusted accordingly. These burning parameters indicate that a ratio of $60 \%(\mathrm{v} / \mathrm{v})$ of ethanol or methanol in the blends gives a more stable combustion, whereas for mixtures above and beyond $60 \%(\mathrm{v} / \mathrm{v})$, modifications are required. On the other side, pure biodiesel can be burned without modifications.

\subsubsection{NO $\mathrm{N}_{\mathrm{x}}$ and unburned $\mathrm{HCS}$ emissions}


The NOx emissions, between $1 \mathrm{ppm}$ to $10 \mathrm{ppm}$, are too low to give relevant information. Unburned HCs emissions also are very low and any trend can be drawn.

\subsubsection{CO emissions}

Figure 4 shows the emission of $\mathrm{CO}$ in the effluent gases according to the different blends made of the variable percentages of diesel, biodiesel, ethanol and methanol. It can be observed first that the combustion of pure diesel or of biodiesel blends presents the smallest production of $\mathrm{CO}$. It can be explained by the similar properties to pure diesel. Literature confirms it: due to oxygenated compounds, the combustion of biodiesels is more complete that the combustion of petroleum fuels, reducing the $\mathrm{CO}$ emissions (Ghorbani et al., 2011). Secondly, the emission of CO increases as the percentage of ethanol (from 20\% to 60\%) increases. It means that the combustion is less complete as the percentage increases. The behavior for blends with methanol is not so clear: the emission of CO increases for percentages of methanol from $20 \%$ to $40 \%$, but decreases for percentages of methanol from $40 \%$ to $60 \%$.

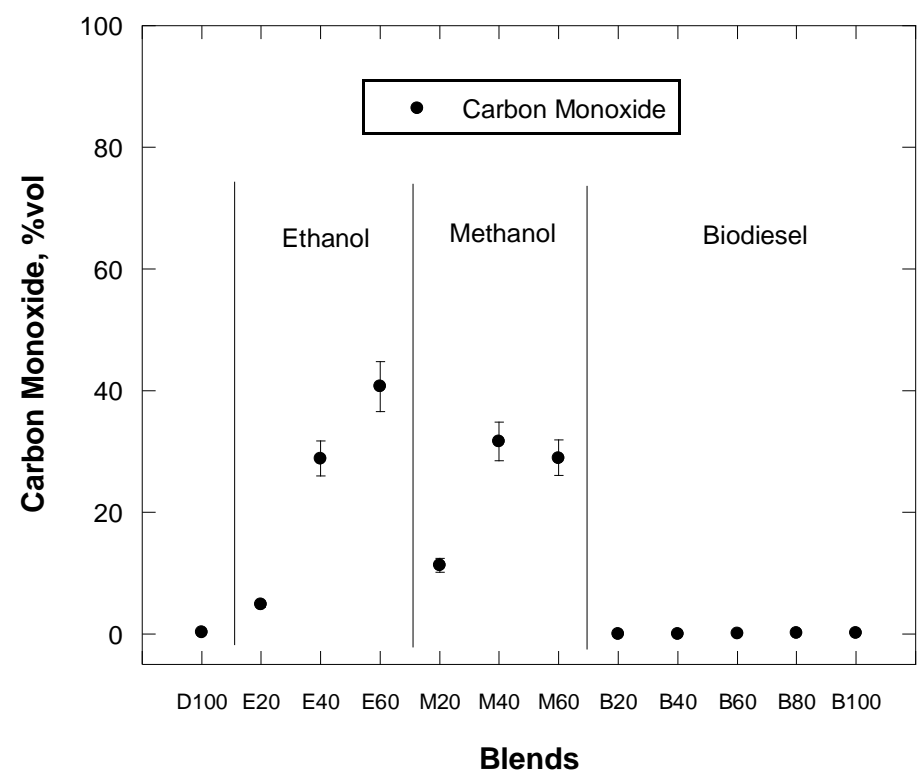

Figure 4: CO emissions in the effluent gases for different blends.

\section{Conclusions}

Under same operating conditions of the isothermal oven, the combustion of pure diesel, diesel-biodiesel, diesel-ethanol y diesel-methanol blends have been studied. It concludes that the wall temperature in the isothermal oven is higher for diesel-biodiesel blends than for pure diesel, whatever the percentage of biodiesel. On the opposite, the wall temperature diesel-ethanol y diesel-methanol blends is lower than for pure diesel. Biodiesel is recommended if a high temperature is expected in an industrial process. Moreover, related to the combustion of biodiesel-diesel blends produce much less $\mathrm{CO}$ than alcoholdiesel blends, and negligible quantities of $\mathrm{HCs}$ and $\mathrm{NO}_{\mathrm{x}}$.

\section{Acknowledges}

The authors would like to express their appreciation to CONICYT-Chile under Fondecyt project 1121188.

\section{References}

ASTM D88, Standard Test Method for Saybolt Viscosity. 
ASTM D92, Standard Test Method for Flash and fire points by Cleveland open cup tester.

ASTM D93, Standard Test Method for flash point by Pensky-Martens closed cup tester.

ASTM D271, Standard Test Method of sampling petroleum and petroleum products.

ASTM D1481, Standard Test Method for density and relative density (specific gravity) of viscous materials by Lipkin Bicapillary Pycnometer.

ASTM D2055, Standard Test Method of Test for Colorfastness of Zipper Tapes to Perspiration

ASTM D4809, Standard Test Method for Heat of Combustion of Liquid Hydrocarbon Fuels by Bomb Calorimeter (Precision Method).

Barnes C.D., Garwood D.R. and Price T.J. (2010), The use of biodiesel blends in domestic vaporising oil burners, Energy, 35, 501-505.

Barroso J., Ballester J. and Pina A. (2010), Some considerations about bioethanol combustion in oil-fired boilers, Fuel Process. Technol., 91, 1537-1550.

Carraretto C., Macor A., Mirandola A., Stoppato A. and Tonon S. (2004), Biodiesel as alternative fuel: Experimental analysis and energetic evaluations, Energy, 29, 2195-2211.

Fang Q., Fang J., Zhuang J. and Huang Z. (2013), Effects of ethanol-diesel-biodiesel blends on combustion and emissions in premixed low temperature combustion, Applied Thermal Engineering, 54, 541-548.

Freedman B., Pryde E.H. and Mounts T.L. (1984), Variables affecting the yields of fatty esters from transesterified vegetable-oils, J. Am. Oil Chem. Soc., 61, 1638-1643.

Freedman B., Butterfield R.O. and Pryde E.H. (1986), Transesterification kinetics of soybean oil, J. Am. Oil Chem. Soc., 63, 1375-1380.

Ghorbani A., Bazooyar B., and Shariati A., Mohammad Jokar S., Ajami H., Naderi A. (2011), A comparative study of combustion performance and emission of biodiesel blends and diesel in an experimental boiler, Applied Energy, 88, 47-4732.

González-González J.F., Alkassir A., San José J., González J. and Gómez-Landero A. (2014), Study of combustion process of biodiesel/gasoil mixture in a domestic heating boiler of $26.7 \mathrm{~kW}$, Biomass and Bioenergy, 60, 178-188.

Methanex Corporation (2006).Technical Information \& Safe Handling Guide for Methanol (2006). Technical Information and Safe Handling Guide for Methanol. http://www.methanex.com/. Visited December, 2011.

Mirade P.S., Daudin J.D., Ducept F., Trystram G. and Clément J. (2004), Characterization and CFD modelling of air temperature and velocity profiles in an industrial biscuit baking tunnel oven, Food Research International, 37, 1031-1039.

Saez A., Flores- Maradiaga A. and Toledo M. (2012), Liquid butane as an alternative fuel for diesel oil burners, Applied Thermal Engineering, 45-46, 1-8.

San José J., Awf Al-Kassir, López Sastre J.A. and Gañán J. (2011), Analysis of biodiesel combustion in a boiler with a pressure operated mechanical pulverization burner, Fuel Processing Technology, 92, 271-277.

San José J., Sanz-Tejedor M.A. and Arroyo Y. (2015), Effect of fatty acid composition in vegetable oils on combustion processes in an emulsion burner, Fuel Processing Technology, 130, 20-30.

Schwab A.W., Bagby M.O. and Freedman B. (1987), Preparation and properties of diesel fuels from vegetable oils, Fuel, 66, 1372-1378.

Shay E.G. (1993), Diesel fuel from vegetable oils: status and opportunities, Biomass Bioenergy, 4, $227-242$.

Tashtoush G., Al-Widyan M.I. and Al-Shyoukh A.O. (2003), Combustion performance and emissions of ethyl ester of a waste vegetable oil in a water-cooled furnace, Appl. Therm. Eng., 23, 285-293. 